\title{
Gelişmiş Ekonomilerde Yeni Normal: Kalıcı Durgunluk
}

Sebahattin KOÇ ${ }^{1}$

\begin{tabular}{|c|c|}
\hline $\begin{array}{c}\text { Geliş Tarihi/ Received } \\
11 / 10 / 2019\end{array}$ & $\begin{array}{c}\text { Yayın Tarihi/ Published } \\
15 / 04 / 2020\end{array}$ \\
\hline $\begin{array}{l}\text { Citation/Atıf: Koç, S., (2020), } \\
\text { Atatürk Üniversitesi Iktisadi } \\
\text { 10.16951/atauniiibd.632199 }\end{array}$ & $\begin{array}{l}\text { Gelişmiş Ekonomilerde Yeni Normal: Kalıcı Durgunluk, } \\
\text { ve İdari Bilimler Dergisi, 34(2): 413-432, DOI: }\end{array}$ \\
\hline
\end{tabular}

Öz: Bu çalışmada gelişmiş ekonomilerde yaşanan kalıcı durgunluk (secular stagnation) kavramı üzerinde durulmuştur. Kavramsal çerçevede ele alınan kalıcı durgunluk, literatür taraması yöntemi ile incelenmiştir. OECD veri sisteminden elde edilen veriler çerçevesinde demografik değișim ve robotik üretim ile kalıcı durgunluk arasındaki ilişkiler belirtilerek her iki kavramın da kalıcı durgunlukla ilişkisi tespit edilmiştir. Kapitalist ekonomik sistemin değişen yapısının (üretim kapitalizminden finans kapitalizmine geçiş) kalıcı durgunluk üzerinde etkili olduğuna dikkat çekilmiştir. Diğer taraftan kalıcı durgunluğun arz kaynaklı mı yoksa talep kaynaklı mı olduğu sorularına yanıt aranmıştır. Kalıcı durgunluğu gidermede etkili olan ekonomi politikalarından para ve maliye politikalarının etkinliği tartışılmış; maliye politikalarının çözümde daha etkili olacağına dikkat çekilmiştir. Kalıcı durgunluğun önlenmesinde; gelir dağılımı eşitsizliğinin giderilmesi, toplumsal faydaya yönelik teknolojik üretimin yaygınlaştırılması, çok uluslu firmaların ekonomi yönetimlerinde etkinliklerinin azaltılması ve toplumsal yarar gözetilerek bağımsız politikaların geliştirilmesi önerilmiştir.

Anahtar Kelimeler: Kalıcı Durgunluk, Sıfır Faiz Bandı, Tasarruf-Yatırım Dengesizliği, Finansal Kapitalizm, Demografik Değişim, Robotik Üretim

\section{New Normal in Advanced Economies: Secular Stagnation}

Abstract: In this study, the concept of secular stagnation in developed economies is emphasized. Secular stagnation, which is dealt within a conceptual framework, is investigated by the literature review method. By examining the relationships between demographic change, robotic production and secular stagnation within the framework of the data obtained from the OECD data system, the relationship between both concepts and secular stagnation is determined. It has been pointed out that the changing structure of the capitalist economic system (the transition from production capitalism to financial capitalism) is effective on secular stagnation. On the other hand, the answer is sought to the question of whether the secular stagnation is stemmed from supply-driven or demand-driven. The effectiveness of monetary and fiscal policies is discussed, which are effective in eliminating secular stagnation, and it is pointed out that fiscal policy would be more effective in the solution. In order to prevent secular stagnation, it is proposed to eliminate inequality of income distribution, to extend technological production towards social benefit, to reduce the effectiveness of multinational firms in economic management and to develop independent policies considering social benefit.

Keywords: Secular Stagnation, Zero Interest Band, Savings-Investment Imbalance, Financial Capitalism, Demographic Change, Robotic Production

${ }^{1}$ Dr. Öğr. Üyesi, Bitlis Eren Üniversitesi, İktisadi ve İdari Bilimler Fakültesi, İktisat Bölümü, https://orcid.org/0000-0002-1911-445X 


\section{EXTENDED SUMMARY}

Background: Today, it is almost impossible for advanced economies to reach their desired growth figures with given sources. This situation has brought questions such as "Does the growth come to end due to technological or environmental reasons?", "Did the individual gains and ambitions of societies deplete the resources of the globe?". Although the answers to these questions cannot be given clearly, it appears that factors such as demographic change, technology (robotic production), increased life expectancy, inequality in income distribution, and decrease in productive labor force have made it almost impossible to achieve the desired growth targets.

Purpose: The aim of this study is to explain what the secular stagnation in developed economies is and to reveal what originates from. In addition, the impact of the demographic change on stagnation, the reasons why the increasing savings do not turn into investments and whether the secular stagnation is supply-driven or demand-driven are emphasized. Besides, the relationship between robotic production and secular stagnation, and the role of monetary and fiscal policy in preventing secular stagnation are discussed. The impact of this recession occurred in developed economies on emerging economies in terms of the central -periphery relationship is also mentioned.

Method: Secular stagnation which is discussed in a conceptual framework, has been examined with the literature review method. In addition, within the framework of the data obtained from the OECD data system, the relationship between the decrease in interest rates, growth figures, demographic change and robotic production and the secular stagnation was tried to be determined. In the literature search, academic google search engine was predominantly used.

Findings: Secular stagnation continues as a dynamic process in developed economies, which somehow affects underdeveloped and developing economies. Demographic change, the almost end of technological level with " the aspect of production enhancing ", income distribution imbalance, the increase in the university graduate youth unemployment, the rise of public and private sector debt levels and increased financialization, in other words, the transformation of production capitalism into financial capitalism, has made today's economic environment inextricable. Especially with the globalization, the huge share of multinational companies in the world economy has started to prevent both political and economic administrations for developing policies in favor of the public. There is a great imbalance in the distribution of public resources. While the individual enterprise, which forms the basis of the liberal economy, transforms a small number of the strong into more stronger; created millions of communities living on the hunger line. It is possible to consider the control of economic management in the hands of this minority as a cause of secular stagnation. 
Conclusions: The goal is to develop growth-stimulating pathways in a recession environment where growth slows down, interest rates fall to almost negative levels, supply and demand are insufficient despite low inflation. What would be the best strategy to promote growth in the current environment? In this sense, while structural reforms are of great importance, macroeconomic adjustment should not be forgotten. Policy makers should pay attention to the fact that monetary policies and fiscal policies that they will implement in their action plans should support each other. Both monetary and fiscal policies, which prioritize the public interest, should be capable of stimulating consumption while at the same time increasing production. Like the private sector activity, the public sector should act with a solution-oriented approach with a social state approach. The distribution of public resources should be based on equality of income distribution and, anti-competitive and monopolistic structures should be eliminated.

\section{Giriş}

Günümüzde gelişmiş ekonomilerin hedefledikleri büyüme rakamlarına ulaşması veri kaynaklarla neredeyse imkansız hale gelmiştir. Bu durum, "Teknoloji ya da çevresel koşullardan kaynaklı nedenlerden ötürü büyümenin sonu mu geldi?", "Toplumların bireysel kazanç ve hırsları yer kürenin kaynaklarını tüketti mi?" gibi soruları da beraberinde getirmiştir. Bu soruların cevabı net bir biçimde verilememekle birlikte görünen odur ki demografik değişim, teknoloji (robotik üretim), artan yaşam beklentisi, gelir dağılımındaki eşitsizlik, üretici işgücünün azalması gibi faktörler arzulanan büyüme hedeflerine ulaşılmasını neredeyse imkansız hale getirmiştir.

2008 finansal krizinden sonra dünya ekonomisinde ve özellikle de gelişen ekonomilerde yaşanan yavaş toparlanma, ekonomistlerin dikkatini çekmiş ve kalıcı durgunluk kavramını gündeme getirmiştir. Yaşanan krizden ve durgunluktan sonra beklenen, hızlı bir toparlanma ile birlikte çıtı ve istihdam seviyesinin hızla trend seviyesine dönmesi iken; bu durum arzulanan seviyelerde gerçekleşmemiştir.

Dünyanın gelişmiş ekonomilerinde gerçekleşen büyüme rakamları gelişmekte olan ekonomilere nazaran çok daha düşük seviyelerde seyretmektedir. Thomas Piketty (2014), 1990-2012 yılları arasında kişi başına üretimdeki büyüme oranlarının Batı Avrupa'da \% 1.6, Kuzey Amerika'da \% 1.4 ve Japonya'da \% 0.7 olduğunu, fakat genel kanı olarak büyüme oranlarının yılda en az $\% 3$ ya da \% 4 olması gerektiğini belirtmiştir. Robert Gordon gibi bazı ekonomistler, kişi başı üretimdeki büyüme hızlarının öncelikle ABD'de olmak üzere gelişmiş ekonomilerde yavaşlamaya mahkum olduğunu ve 2050 ile 2100 yıllarına kadar bu oranın \% 0.5 'ın altına inmesinin söz konusu olabileceğini belirtmişlerdir.

2009'da, ABD'deki faiz oranlarının altı yıl boyunca sıfira yakın kalacağını, Avrupa'daki kilit faiz oranlarının negatif olabileceğini ve G-7 merkez bankalarının bilançolarının toplu olarak 5 trilyon dolardan daha fazla 
artacağ1 öngörülmemiştir. ABD'de borç/GSYİH oranı 2008 'de \% 41 'den 2016 'da \% 74'e, Japonya'da \% 95'ten \% 126'ya ve Avrupa'da \% 47'den \% 70'e yükselmişstir (Summers L., 2016). Gelişmiş sanayi toplumlarında yaşanan bu durumu ilk defa Alvin Hansen kalıcı durgunluk (secular stagnation) olarak ifade etmiş ve bu kavram günümüzde Larry Summers tarafindan tekrar gündeme getirilmiştir.

$\mathrm{Bu}$ çalışmanın amacı gelişmiş ekonomilerde yaşanan kalıcı durgunluğun ne olduğu açıklamak ve nelerden kaynaklandığın ortaya çıkarmaktır. Ayrıca yaşanan demografik değişimin durgunluğa olan etkisi, artan tasarrufların yatırıma dönüşmemesinin nedenleri ile kalıcı durgunluğun arz kaynaklı mı yoksa talep kaynaklı mı olduğu üzerinde durulmuştur. Diğer taraftan çalışmada robotik üretim ile kalıcı durgunluk ilişkisi ve para politikası ile maliye politikasının kalıcı durgunluğu önlemedeki rolü ele alınmıştır. Gelişmiş ekonomilerde yaşanan bu durgunluğun merkez çevre ilişkisi bakımından gelişmekte olan ekonomilere olan etkisine de değinilmiştir.

\section{Kalıcı Durgunluk}

1930'lu yılların sonlarında ilk defa Harvard ekonomistlerinden Keynesyen ekonominin temsilcisi olan Alvin Hansen tarafindan kalıcı durgunluk teorisi ileri sürülmüştür. Hansen, 1930'lardaki çöküş ekonomilerinin, yavaşlayan yenilikler, yavaşlayan inovasyon ve yaşlanan nüfusun bir ürünü olarak durgunluğa mahkum olduğunu ifade etmiştir. Bu dönemde zengin ülkelerde tasarrufların arttığı ancak bunların yatırıma dönüşmediği dikkat çekmektedir. Günümüz ekonomistlerinden Summers da benzer bir değerlendirmede bulunarak; gelişmiş ülkelerin çeşitli nedenlerden dolayı tasarruf fazlalığı yaşadığını belirtmiş ve özellikle de gelişmekte olan ekonomilerdeki döviz rezervlerindeki artışın dünya ekonomisinde tıkanmaya neden olduğunu belirtmiştir.

Kalıcı durgunluk; gelişen ekonomilerde düşük faiz oranları ile düşük enflasyona rağmen büyüme oranlarının beklenenin altında gerçekleşmesi şeklinde kendini göstermektedir. Özellikle Japonya, Almanya, İngiltere ve Amerika Birleşik Devletlerinde yaşanan bu durgunluğu çeşitli etmenlerle ilişkilendirilebilir. Kalıcı durgunluğa gösterge olarak sıfır bandına yakın hatta negatif reel faiz oranlarını göstermek mümkündür. İlgili ülkelerde tasarruflarda artış dikkat çekerken yatırımlarda bir azalma olduğu söylenebilir.

Tablo 1: Bazı Gelişmiş Ekonomilerde Büyüme Oranları (\%)

\begin{tabular}{llllllllllll}
\hline Ülkeler/Y1llar & 2007 & 2008 & 2009 & 2010 & 2011 & 2012 & 2013 & 2014 & 2015 & 2016 & 2017 \\
\hline ABD & 1.11 & 1.11 & 1.00 & 1.08 & 1.26 & 1.20 & 1.38 & 1.23 & 1.08 & 0.98 & 0.95 \\
Almanya & 0.83 & 0.89 & 0.74 & 0.72 & 0.82 & 0.78 & 0.98 & 0.97 & 0.73 & 0.74 & 0.86 \\
İngiltere & 0.63 & 0.70 & 0.61 & 0.73 & 0.68 & 0.68 & 0.73 & 0.72 & 0.66 & 0.65 & 0.67 \\
Japonya & 1.06 & 1.06 & 1.08 & 1.11 & 1.08 & 1.15 & 1.11 & 1.06 & 1.12 & 1.22 & 1.20 \\
\hline
\end{tabular}

Kaynak: OECD Veri Tabanı 
Tablo-1 de kalıcı durgunlukla karşı karşıya olan ekonomilerin büyüme oranları verilmiştir. Ortalama olarak bakıldığında 2007-2017 yılları arasında büyümenin \%1 civarında olduğu dikkat çekmektedir. Kalıcı durgunluğun temel göstergesi niteliğinde olan yavaş büyüme oranları ilgili ülkelerin bu durgunlukla karşı karıya olduğunun bir göstergesi niteliğindedir.

"Kalıcı durgunluk" terimi genellikle iki kelimenin ötesine geçen oldukça spesifik ekonomik bir anlam taşır. Son yıllarda, bu terim genellikle yetersiz talep nedeniyle zayıf kaynakların varlığına ve içsel mekanizmaların (kurala dayalı para politikası da dahil olmak üzere) makul olmayan bir çıktı açığını oldukça kısa bir sürede kapatmaması anlamında kullanılmıştır. "Durgunluk" ekonomik aktivitenin durgunluğunu ifade ederken, bu tanım, durgunluğun hangi karşılaştırma ölçütüne göre belirlendiği sorusunu gündeme getirmiştir. Makroekonomik modellemede ölçüt olarak; emeğin tam istihdamını, sermayenin tamamen kullanılmasını veya potansiyel çıtının bir tahmin olarak ele alınmasını kullanmak mümkün olabilir. Fakat bu kavramlar bir model içinde anlam kazansa da ampirik olarak doğrudan gözlemlenemezler. Bu nedenle, durgunluğu tarihsel ölçütlere göre tanımlamak daha açıklayıcı olacaktır. Son tahlilde ekonominin, önceki dönemlerde olduğu kadar daha iyi bir performans göstermemesini durgunluk olarak ifade etmek yanlış olmayacaktır. Büyüme oranlarını örneğin kişi başına düşen GSYİH büyümesi temel ölçüt olarak ele alınabilir. Diğer taraftan işgücüne katılım oranının azalması da durgunluğa işaret edebilir (Cynamon ve Fazzari, 2017).

Bir başka tanıma göre; tasarrufların sadece negatif reel faiz oranlarında yatırıma eşit olabileceği ancak bunun da faiz oranları ve düşük enflasyon üzerindeki sıfır düşük sınır kısıtı nedeniyle gerçekleşmeyecek bir denge olmasını kalıc1 durgunluk olarak ifade etmek mümkündür (Jimeno, Smets, ve Yiangou, 2014).

Reel faiz oranının aşağı yönlü olmasından kaynaklı olarak, tasarrufların istenen yatırım oranlarından yüksek çıkması ve bunun sonucunda kalıcı bir çıtı açığı ile birlikte yavaşlayan büyüme oranları kalıcı durgunluk olarak ifade edilebilir.

Paul Krugman (2010) durgunluğu; halkın bir bütün olarak nakit biriktirmeye çalışmasından kaynaklanan bir sorun olarak tanımlamıştır. $\mathrm{Bu}$ da yatırımlardan daha fazla bir tasarruf anlamına gelmektedir. Diğer taraftan Krugman büyüme durgunluğunu ise, bir ekonominin büyümesine rağmen bu büyümenin kapasite artışının kullanılmasına yetmeyecek hızda olması olarak değerlendirmiştir. $\mathrm{Bu}$ durum ise giderek daha fazla makine ve işçinin atıl kalması sonucunu ortaya çıkarmaktadır.

\subsection{Demografik Değişim ve Kalıcı Durgunluk}

Demografik yapı bir ülkedeki nüfus yapısını göstermektedir. Bir ekonomide aktif işgücü durumu, genç nüfus, emekli toplamı, yaşlılık oranı ve yaşam beklentisi ile üretim kapasitesi ve toplam çıktı arasında ilişki kurmak 


\section{Gelişmiş Ekonomilerde Yeni Normal: Kalıcı Durgunluk}

mümkündür. Artan yaşam beklentisi ve düşük doğum oranları gelecek kaygısını beraberinde getirerek tasarruf arzını tetiklerken; yaşlanan nüfus oranının yükselmesi aktif işgücü kaybına neden olarak çıktı kaybını ortaya çıkarabilmektedir. Kısaca demografik yapı büyüme ve reel oranlar için önem arz etmekte ve demografik veriler tasarruf, yatırım ve çıktı yapısı üzerinde etkili olabilmektedir.

Hem gelişmiş ekonomilerin hem de dünyanın geri kalanının hızlı yaşlanması, gelecek birkaç on yılın en tehlikeli ekonomik hastalıklarından biri olarak görülmektedir. Alvin Hansen (1939) gelişmiş ekonomilerin "kalıcı durgunluk" tarafından etkilendiğini kısmen yaşlanan bir nüfusun yatırımlara oranla fazla tasarruf sağladığını düşünürken; Gordon (2014) demografik değişimi, gelişmiş dünyadaki ekonomik büyümeyi yavaşlatan ilk "rüzgar" olarak tanımlamıştır.

Gelişmiş ülkelerde, artan yaşam beklentisi ve düşük doğum oranları nüfusun yaşlanmasını beraberinde getirmiştir. 1970'lerde ABD' de nüfusun genç olması ve gelirlerin artacağına dair beklentiler, borçların ödenmesinde ve emeklilik sigortası ödemelerinde herhangi bir sıkıntının olmayacağ görüşü ile tasarrufların çok düşük seviyelerde olmasını sağlamış ancak günümüzde bu oran yükselmiş ve tasarruflar GSYH'nin neredeyse yarısına ulaşmıştır. Yaşlanan nüfus, beraberinde hane halkının tasarruflara yönelmesini sağlarken bu tasarruflar gelecek kaygısından kaynaklı olarak yatırımlara beklenen oranlarda dönüşmemiştir.

On dokuzuncu ve yirminci yüzyılda ABD'de nüfus artış hızının yüksek olması reel üretimin tetikleyicisi olma işlevi taşırken aynı zamanda toplam talebi de arttırıcı bir etki yapmıştır. Bu dönemlerde ekonomik canlılı̆̆ın olduğunu söylemek mümkündür. Alvin Hansen'a göre artan nüfus hızı kişi başına düşen reel gelirdeki artışın bir kısmının sebebi olurken aynı zamanda yatırım üzerinde de artan tüketimin etkisiyle sermaye oluşumunu tetiklemiştir. Dolayısıyla, nüfus artışının, sermaye oluşum hacmini arttırmada hem doğrudan hem de dolaylı etkiye sahip olduğunu söylemek mümkündür. Günümüzde nüfus artış hızında yaşanan yavaşlama büyümeyi hem demografik hem de ekonomik olarak yavaşlatmıştır. Bu durum demografik değişimin kalıcı durgunlukta önem teşkil ettiğini göstermektedir. 


\section{A. Beklenen Yaşam Süresi}

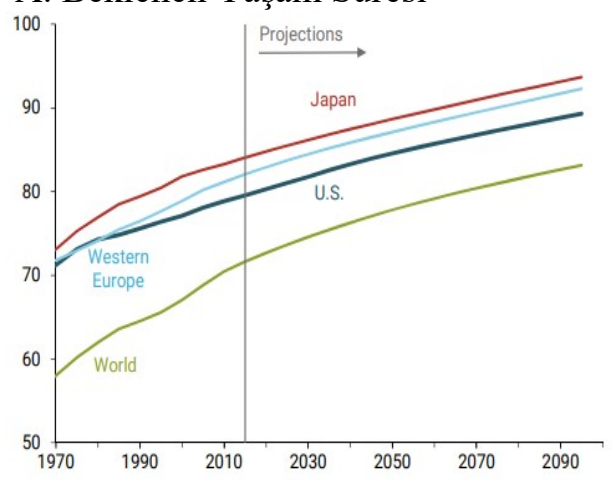

B. Nüfus Artışı Oranı



Grafik 1: Gelişen Ekonomilerde Demografik Değişiklik( Carvalho ve diğ.)

Yukarıdaki grafikler hızla yaşlanan nüfusu gösterirken; tahminler, bu değişikliklerin gelecekte bir süre devam edeceğini ve derinleşeceğini göstermektedir. Grafik 1. A'da görüldüğü gibi doğumdan sonra yaşam beklentisi 1970'li yıllarda 60 yaş ile 75 yaş arasında değişirken günümüzde bu oran 65 yaş ile 85 yaşa arasına yükselmiştir. Bu durum aktif çalışan nüfustan emekli oranının artması sonucunu doğururken emeklilikte geçen sürenin de yükselmesine neden olmuştur. Yaşlanan nüfusun gelecek kaygısı bireyleri tasarrufa yönlendirmekte ve birikimlerin yatırımlara dönüşmesine engel olabilmektedir. Diğer taraftan Grafik 1. B'de görüldüğü gibi nüfus artış oranının; Japonya, Batı Avrupa, ABD ve Dünya ortalaması olarak 70'li yıllardan geleceğe doğru azalış trendinde olduğu dikkat çekmektedir. Emeklilikte geçen sürenin artması emekli maaşları konusunda belirsizliğe yol açarken artan yaşam beklentisi, hem çalışanların hem de emekli nüfusun kişi başı tasarruflarında önemli bir artışa yol açabilmektedir (Jimeno vd, 2014).

$\mathrm{Bu}$ durum karşısında son on yılda gelişmiş ekonomilerde hükümet politikaları dört önemli konuda değişikliğe uğramıştır. Birincisi, devlet borcu GSYİH'nın yaklaşık \% 20'sinden \% 70'ine yükselmiştir. İkincisi, sosyal güvenlik ve sağlık sistemleri yoluyla yapılan yaşlılık ödemeleri, toplam sosyal harcamalardaki artışın aslan payını hesaba katarak sırasıyla \% 4'ten \% 7'ye ve GSYİH'nın \% 2.5'inden \% 4'üne yükselmiştir. Üçüncü olarak vergi politikalarında önemli değişiklikler olmuş; zengin ekonomilerdeki etkili kurumlar vergisi oranları, yüzyılın başında \% 32'den \% 24'e düşmüştür. Son olarak da 1990'da 12 OECD ülkesinde uygulanan servet vergisi, bugün sadece 4 ülkede uygulanır hale gelmiştir (Rachel ve Summers, 2019). Vergi yükünün hafifletilmesi, kamu harcamalarının yükseltilmesi ve yaşl1lık ödemelerinin yükseltilmesi bir taraftan kalıcı durgunluğu gidermeye yönelik kamu politikaları olarak dikkat çekerken diğer taraftan durumdan faydalanan kurumların reel yatırım yerine özellikle finansalizasyon sonucu finansal yatırımlara ve tasarrufa 
yönelmelerine neden olmuştur. $\mathrm{Bu}$ durum uygulanan politikaların kalıcı durgunluğu gidermede beklenen sonucu vermemesine neden olmuştur.

Gordon (2014) kalıcı durgunluğu ABD için yorumlarken; ABD'yi yavaş hareket eden bir kaplumbağaya binen ve ilerlemeye çalışan bir ülke olarak nitelendirirmiş ve konu ile ilgili olarak politikacıların yapacakları çok da bir şeylerinin olmadığını belirtmiştir. Büyümenin önünde engel olarak; demografi, eğitim, eşitsizlik ve devlet borçlarını gösteren Gordon; bu faktörlerin, 18912007 yılları arasında ortalama \% 2 olan reel GSYİH büyüme oranını 2032 yılına kadar ortalama \% 0,9 seviyesine indirebileceğini belirtmiştir.

Demografik rüzgarın, ekonomik büyüme üzerindeki uzun vadeli nicel etkisi tartışılmaya devam etmektedir. Ancak nüfus artış hızındaki yavaşlamanın ekonomiyi yavaşlattığı sonucu dikkat çekmektedir. 1970'li yıllardan sonra azalan üretim hızı ve verimlilik artışındaki yavaşlama, artan doğum oranları ile gençlerin iş hayatına girmesi sonucunda dengelenmiştir. Ancak 2004 yllından sonra yapılan araştırmada doğum oranlarındaki yavaşlama, genç iş gücünde azalmaya neden olurken; bunun sonucunda büyüme hızı yavaşlamış ve reel GSYIH artış oranı \%1,2 oranında azalmıştır. Kısaca 70'li yıllarda yaşanan bebek patlamasıyla gelen neslin günümüzde emekli olması, üretimdeki azalmanın nedeni olarak demografik etkinin bir sonucu olduğu söylemek mümkündür (Gordon, 2014).

Eğitimin büyüme üzerindeki olumsuz bir etkisi var mıdır? Özellikle lise ve üniversite mezunlarının sayısının artması üretken "fabrikada çalışacak" işgücünde azalış meydana getirmektedir. Ancak üniversite mezunu olup da kendi birikim ve tecrübesine göre iş bulamayan yeni bir işsiz ordusunun ortaya çıkması, insanların garson ya da taksi şoförü gibi işlerde çalışmasına neden olmaktadir.

Gelir dağılımında eşitsizliğin artmasını, kalıcı durgunluğun bir nedeni olarak değerlendirmek mümkündür. Özellikle şirket ceoları, sanatçılar, futbolcular vb. milyonlarca dolar gelir elde ederken toplumda üst gelir gruplarının yarattığ sermaye miktarı hızla artmakta ve reel üretim sonucu yaratılan sermaye yerine bu şekilde elde edilen gelir, borsalarda bir sermaye balonu yaratmaktadır. Belirli bir üst gelir grubunun üretimden yoksun olarak yarattıkları sermaye daha önce de belirttiğimiz gibi finansal kapitalizmin bir sonucu olarak ortaya çıkmıştır. Bu şekilde elde edilen yüksek kazançlar doymamış piyasalara akın ettiği için doymuş piyasalardan bir sermaye kaçışı gerçekleşmektedir. Gelirleri çok yüksek olanların tüketme eğilimi nispeten düşüktür ve ABD'de elde edilen gelirlerin neredeyse tamamı gelirleri çok yüksek olanlara gitmiştir.

ABD'de toplam federal borcunun GSYİH'e oranının gittikçe yukarıya doğru çıkması bu ülke açısından kalıcı durgunluğu etkileyen faktörlerden biri olarak değerlendirmek mümkündür. Potansiyel gerçek GSYİH büyümesi, tahmin edilenden çok daha yavaş olduğu için, gelecekteki vergi geliri daha yavaş büyüyecek, borç / GSYH oranındaki paydaki borcu artıracak, payda daha 
yavaş büyüyecek ve oran 2030'ların sonunda \% 150'ye ulaşabilecektir (Gordon, 2014). Bu durum devletin gücüne ve büyüklüğune bakılmaksızın ilgili ülke için büyümenin önünde önemli bir engel olmaya devam edecektir.

Gelişmiş olan ülkelerdeki yaş ortalamasının yükselmesi üretimi yavaşlatıcı bir etki yaratırken; bu sorunun üstesinden gelmek için Avrupa'nın bazı ekonomileri, özellikle Almanya, yurt dışından işgücü transferi yöntemiyle aktif işgücü sağlama yoluna gitmişlerdir. Fakat kalıcı durgunluğun sebeplerinden biri olarak görülen yaşl1lığın üretim hacmini doğrudan etkileyemeyeceği, çünkü bu tür ekonomilerde robotik üretimin bu iş gücü kaybını önleyebileceğini savunan bazı çalışmalar yapılmıştır. Bu konuda Daron Acemoğlu yaşlanma ile birlikte üretimin azalmadığını; özellikle yaşlanan nüfus ile ekonomik büyüme arasında doğrudan bir ilişki olmadığını ve yaşlanan ülkelerin robotik üretime yöneldiğini belirtmiştir.

\section{2. Üretim Kapitalizminden Finans Kapitalizmine Geçiş ve Kalıcı Durgunluk}

Kapitalizm her şeyden önce tarihsel bir toplumsal sistemdir. Kapitalizm sözcüğü kapitalden türemiştir. $\mathrm{Bu}$ anlamda sermayenin kapitalizmde kilit bir öğe olduğunu kabul etmek yerinde olacaktır. Sermaye birikmiş zenginlikten başka bir şey değildir (Wallerstein, 2016). Fakat günümüzde birikmiş zenginliğin türü büyük bir değişiklik göstermiştir. Daha önceleri sermaye stoku, fabrikalardaki makineler ve üretim faktörleri sonucu oluşturulan mal stokları zenginliğin göstergeleriyken; günümüzde sermaye finansal varlıklara dönüşmüş, fabrikaların yerini menkul kıymet borsaları almaya başlamıştır. Artık zenginliğin göstergesi üretim atölyeleri, fabrikalar ve buralarda çalıştııllan işçi sayısından ziyade menkul kıymet borsalarında ne kadar finansal varlığa sahip olunduğudur. Bu durum kapitalist sistemin dönüşümü ile ilgili olarak da değerlendirilebilir. Üretimin yavaşlaması, sistemin her şeyi metalaştırdığı ve kapitalist ekonomik sistemin kendi zitlarını yok ettiği bir ortamda akıllara "Kapitalizm kendi sonunu mu getiriyor?" sorusu gelmektedir.

Günümüzde çok uluslu şirketlerin egemen olduğu ve kamu otoritesinin ekonomi üzerinde etkisinin azalığı bir ortamda, tüm bireylerin çıkarlarını göz önünde bulunduran bir yapıdan bahsetmek mümkün değildir. Alvin Toffler (1996)'a göre sanayi ülkelerinde giderek artan miktarlardaki ekonomik kararın devletin kontrolünden çıkması, demokratik sorumluluk bilincinin azalışının bir nedenidir. Bir ülke halkının o ülkenin ekonomik hayatına şekil vermesi demokrasinin önemli temellerinden biridir. Her ne koşulla olursa olsun bu prensibin çiğnenmesi ülkeyi sömürge haline getirebilecektir.

$\mathrm{Bu}$ bağlamda yaşanan ekonomik durgunluğun bir nedenini de finansalizasyon olarak ifade etmek mümkündür. Çünkü sanayi devriminden itibaren üretim merkezli olarak ortaya çıkan kapitalizm günümüzde üretici özelliğini kaybederek yeni bir nitelik kazanmıştır. Geçmişin feodal beyleri üretim kapitalizmi döneminde fabrikatöre dönüşmüş ve oluşan zengin sınıf yeniliği ve teknolojiyi destekleyerek devasa üretim makinalarının desteğiyle 
toplam üretimi arttırıcı faaliyetlerde bulunmuşlardır. Ancak 80'li yıllardan sonra İngiltere de Margret Teacher ve ABD'de Ronald Reagen döneminde yeni bir kapitalist ekonomik sistem ortaya çıkmıştır. $\mathrm{Bu}$ dönemde yeni pazar arayışları dışa açık ekonomiler ve küreselleşme olgusu, bir dönemin aydınlanmacı ve üretici kapitalist zenginlerinin dönüşüme uğramalarına neden olmuş ve paradan para kazanan bir yapı ortaya çıkmıştır. Sermaye piyasalarının yaygınlaşması uluslararası menkul kıymet pazarları dediğimiz borsaların gelişmesi; yeni zengin sınıfın her yerde finansal yatırım yapma şansı elde etmelerini sağlamış, bunun sonucunda sermaye doymuş gelişmiş ekonomilerden yeni pazarlara yönelerek bu ekonomilerde kırılgan bir yapı meydana getirmiştir. Yükselen finansallaşma oranları beraberinde oluşan tasarrufların reel yatırımdan ziyade finansal yatırımlara yönelmesini sağlamıştır. Artan finansallaşma hem eşitsizliğe neden olmuş hem de sermaye balonlarının oluşmasına neden olmuştur.

Firmalar artan kârlarını üretime kaydırıp yeni reel yatırımlar yapmak yerine, elde ettikleri birikimleri spekülatif amaçlı finansal yatırımlara yönlendirme yolunu seçmişlerdir. Ancak bu tür yatırımlar faiz oranlarının çok düşük beklenen getirinin arzulanan seviyede olmadığı doymuş piyasalar yerine risk iştahının yüksek olduğu dönemlerde doymamış piyasalara doğru kaymıştır. $\mathrm{Bu}$ yatırımlar kalıcı olmadıkları için doymamış piyasalardaki sermaye hareketlerinin volatilitesinin yüksek olmasına neden olmuştur.

Yükselen eşitsizlik ve finansalizasyon, sermaye birikimi ve büyüme kaybının arkasında yatan ana sebepler olmuş ve bunları frenlemiştir. Finansalizasyon başka bir ifade ile finansallaşma, finansal güdülerin, finansal kurumların ve finansal piyasaların hem ulusal hem de uluslararası düzeyde genel ekonomik işlemler içerisinde öneminin artması şeklinde tanımlanmaktadır. Gelişen finansal sektörün gelir dağılımı ve toplam talep üzerinde etkili olduğu ileri sürülmektedir. Gelişmiş ekonomilerde finansallaşma süreci ile birlikte şirketlerin artan kârları spekülatif girişimlerden kaynaklı olarak yatırımlara dönüşmemiştir (Onaran, 2016).

\subsection{Tasarruf-Yatırım Dengesizliği ve Kalıcı Durgunluk}

Son y1llarda özellikle 2008 küresel finans krizinden sonra gelişmiş ekonomilerde tasarruf oranlarının hızla yükseldiği dikkat çekmektedir (Grafik 2). 2008 finansal krizinden sonra ABD, Japonya ve İngiltere'de negatiflere düşen tasarruf oranları daha sonra yükselmiş ve yükselmeye devam etmektedir. Yavaşlayan büyümenin önemli bir nedeni yatırımlara dönüşmeyen tasarruf oranlarındaki artış olarak gösterilirken gelişmiş sanayi ekonomilerde artan demografik değişiklik tasarrufların hızla yükselmesine neden olmuştur. 


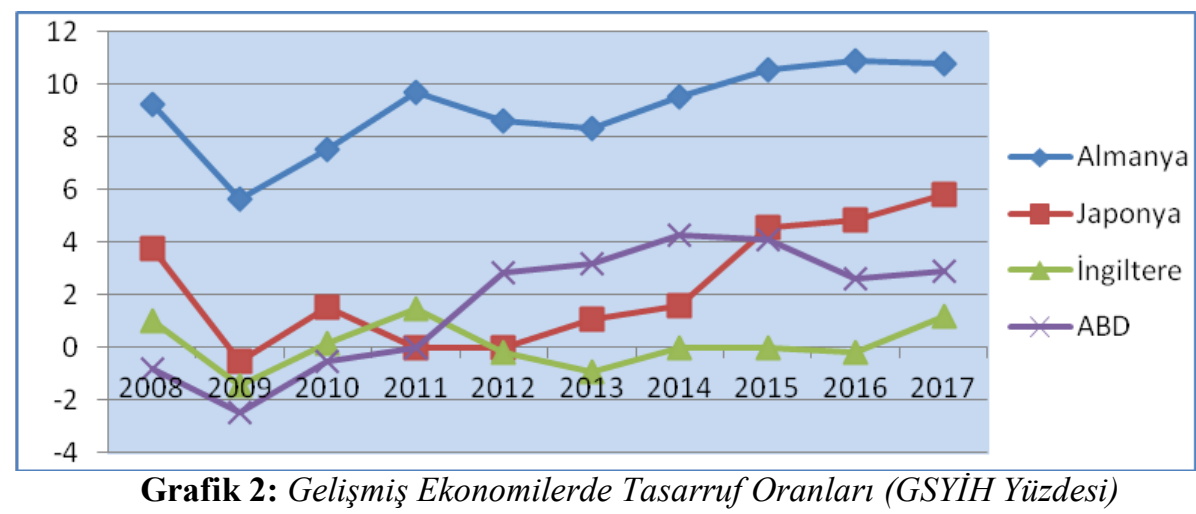

Alvin Hansen gelişmiş ekonomilerin "kalıcı durgunluk" tarafindan etkilendiğini, kısmen yaşlanan bir nüfusun yatırımlara oranla fazla tasarrufa yöneldiğini ifade etmiştir (Acemoglu ve Restrepo, 2017).

Gelişmiş ekonomilerde reel faiz oranlarının sıfır bandında olması, üretim maliyetlerini ucuz finans kaynağı açısından düşürürken, artan finanslaşma ile birlikte özel tasarrufların yatırımlara dönüşmesinde yeterli bir kaldıraç olamamıştır. Bunun nedeni gelişmiş ekonomilerdeki düşük reel faizlerin finansal yatırımcı niteliği kazanan yatırımcıların yatırım yapma konusunda çekingen davranmalarına neden olmuştur. Bu durumda, küresel tasarruflardaki bir artış, küresel GSYİH üzerinde olumsuz bir etkiye neden olmuştur.

Gelişmiş ülkelerdeki nüfus artış hızının yavaşlamaya devam etmesi sonucunda, yaşlanan nüfusun yatırım talebinin azaldığını söylemek mümkündür. Gelişmekte olan ülkelerin rezerv biriktirmeleri, finansal kriz sonrası daha katı sermaye ve teminat gerekliliklerinin güvenli varlıklara olan talebi arttırması, eşitsizliğin artması ile artan tasarruf eğilimi, vergi öncesi reel faiz oranlarının, enflasyonun azalması ile çekiciliğinin artması ve krizin mirasına bağlı olarak tasarruf sahiplerinin getirileri ile borç alanların maliyetleri arasında finansal aracılık maliyetlerinin artması gibi faktörler tasarruf arzını yükseltmiştir. Dolayısıyla, denge reel faiz oranlarının geçmişte olduğundan daha düşük olmasını beklemenin birçok nedeni ortaya çıkmıştır. Düşük denge reel faiz oranları, düşük enflasyon oranları ile birleştiğinde, sıfır-düşük sınırın, geçmişte olduğundan daha fazla yeterli toplam talep elde etmede bir kisıtlama olacağı anlamına gelmiştir (Summers, 2015).

Durgun toplam talep sorununun bir sonucu olarak hanelerin yeterince harcama yapmadıkları ve firmaların sıfira yakın faiz oranlarında bile yeterince yatırıma gitmedikleri dikkat çekmektedir. Gelirleri çok yüksek olanların tüketme eğilimi nispeten düşüktür. ABD'de ve gelişmiş ekonomilerde elde edilen gelirlerin neredeyse tamamına yakını, gelirleri çok yüksek olanlara gitmektedir. Gelir dağılımındaki bu dengesizlik toplam talebe azaltıcı bir etki yapmaktadır. Sonuç olarak bakıldığında faiz oranlarının pozitif olması, firmaların yatırım yapmaktan kaçınarak tasarruflara yönelmesini sağlarken; 


\section{Gelişmiş Ekonomilerde Yeni Normal: Kalıcı Durgunluk}

gelişmiş ekonomiler düşük faiz oranlarına yönelmektedir. Buna rağmen tatmin edici büyüme oranları elde etmek için yatırımlar yeterli seviyeye çıkmamaktadır (Eichengreen, 2014).

Modern kapitalizmin başlangıç safhalarında, hem sermaye oluşumunun derinleșmesi hem de genişleme süreçleri yan yana gelişmekteyken; ilerleyen aşamalarında ekonomiyi bir bütün olarak ele alan derinleşme süreci hızla azalmıştır. Nüfus artışının hızlı bir şekilde durması beraberinde genişleme sürecini de yavaşlatmıştır. Üstelik sermaye tasarrufu sağlayan icatların, birçok sektörde sermaye oluşumunun, üretimdeki artışın gerisinde kalmasına neden olmuştur (Hansen, 1939). Nüfus artışının kişi başına düşen reel gelirdeki artışın bir kısmından sorumlu olması, yatırım üzerindeki artan tüketimin etkisiyle sermaye oluşumunu teşvik etmektedir. Dolayısıyla, nüfus artışının, sermaye oluşum hacmini teşvik etmek için hem doğrudan hem de dolaylı olarak hareket etmiş olması oldukça muhtemeldir.

\subsection{Robotik Üretim ve Kalıcı Durgunluk}

Alvin Hansen "Tam istihdamı sürdürmeye yeterli özel yatırım firsatları bulmak istiyorsak, geçmişten daha hizlı bir teknolojik ilerlemeye geri dönmeliyiz." söylemi ile kalıcı durgunluğu önlemede teknolojinin önemini vurgulamışır. Ancak teknolojik gelişme hızı toplam üretimi etkileme açısından değerlendirildiğinde günümüzde yeterli bir seviyeye ulaşamamıştır. Sanayi devrimiyle başlayan makineleşme toplam üretimi ve dolayısıyla büyümeyi tetiklerken; günümüz teknolojileri aynı hızda üretimi tetiklememektedirler. Teknolojik gelişmeyle birlikte ortaya çıkan robotik üretim bir taraftan yaşam kalitesini arttırırken diğer taraftan yeni iş kollarının ortaya çıkmasını zorunlu hale getirmiştir. Gelişmiş ekonomiler robotik üretimden işgücü yetersizliğinden kaynaklı olarak olumlu faydalanmışlardır. Ancak aynı teknolojilerin gelişmekte olan ve aktif işgücüne sahip olan ülkelere yansıması aynı iyimserlikle olmamaktadir.

Ekonomistlerin bir kısmı, yeni teknolojilerin büyük bir kısmının iş olanaklarını azaltmadığını; daha ziyade teknik gelişmelerin makroekonomik politikalarla etkin talebin karşılanması halinde, özellikle yok ettikleri kadar yeni iş olanakları yaratacağına inanmaktadırlar. $\mathrm{Bu}$ tartışma, yakın zamanda robotlarla ilgili bir konuda tekrar gündeme gelmiş ve verimlilik artışının 2008 krizi sonrasında genişlemede yeterli bir etkiye sahip olmaması gerçeği, teknik değişimin çok hızlı olmadığının kanıtı olarak kabul edilmiştir(Galbraith, 2018).

Robert Gordon (2012) kalıcı durgunluğu bu bağlamda ele almış ve kalıc1 durgunluğu tüm büyük icatların yapılmış olması şeklinde tanımlamıştır. Elektriğin, içten yanmalı motorun ve iç mekan tesisatının, verimliliği artırmak ve yaşam standartlarını yükseltmek için internet patlamasının ürettiği her şeyden çok daha önemli olduğunu; ayrıca günümüzdeki, kişisel elektroniklerin günlük eğlenceler için harika olduğunu, fakat üretkenliği artırmadığını belirtmiştir. Görünen odur ki gelecekte elektriğe veya içten yanmalı motora 
eşdeğer yeni büyük bir buluş imkanı kalmamıştır (Eichengreen, 2014). Yakın geçmişteki ve günümüzdeki teknolojik dalgaların üretim biçimlerine müdahalesi öncekiler kadar kökten değildir ve dolayısıyla ekonomik büyümeye ve verimliliğe yaptıkları katkı daha da azalmıştır. Bu durumu teknolojik verimsizlik olarak değerlendirmek mümkündür.

Alvin Hansen tam istihdamın sürdürülmesi ve özel yatırım firsatlarının bulunup değerlendirilmesi için geçmişten daha hızlı bir teknolojik üretim hızının yakalanmasının gerekli olduğunu belirtmiştir. Ayrıca nüfus artı̧̧ hızının yavaşlaması ile birlikte yapılan yeniliklerin büyük sermaye harcamalarını karşılayamamasını, o dönemdeki ekonomik iyileşmelerin tam istihdama ulaşmamasının nedeni olarak açıklamıştır (Gomme vd., 2015).

Kaynakların mevcudiyeti, kalitesi ve maliyeti önemlidir - neoklasik büyüme teorisi tarafından ihmal edilse de - tüm canlı sistemler kaynakları çıkarır ve israf eder. Problem, bu süreci ne kadar verimli bir şekilde yönettikleri, hangi araç dağıtım araçlarıyla ve hangi ölçekte, hangi zamanda teknolojik fırsatlara bağlı kararlar olduklarıdır. Bu nedenle, teknik gelişmelerin kesin karakterini sorgulamak ve soyut karakterizasyondan veya belirsiz matematiksel sembollerden memnun olmamak önemlidir. Yatırım ortamı önemlidir, çünkü büyük organizasyonlar önceden plan yapmalıdır ve planlarının kalitesi ve karakteri zamandan etkilenir. Ekonominin finansal atardamarları önemlidir, çünkü tıkanırlarsa sistemi çökertme kapasitelerine sahiptirler (Galbraith, 2018).

\subsection{Arz ve Talep Yönlü Kalıcı Durgunluk}

Kalıc1 durgunluğun üretim yetersizliğinden mi yoksa tüketim yetersizliğinden mi kaynaklandığı konusu kalıcı durgunluğun arz yönlümü yoksa talep yönlü mü olduğu sorusunu gündeme getirmiştir. Özellikle ABD, Japonya ve Almanya gibi gelişmiş ekonomiler incelendiğinde, demografik yapılarında yaşlı nüfusun artması dikkat çekmektedir. Bu ülkelerde yaşam beklentisi artarken emeklilikte geçen süre de yükselmiştir. Hal böyle olunca düşük faiz oranları ve düşük enflasyona rağmen tasarruflarda artışın olduğu ancak bu tasarrufların üretime dönüşmediği dikkat çekmektedir. Uzun yaşam beklentisi ve ardından gelen uzun süreli emeklilik hayatı, günlük tüketimin ertelenmesine ve gelecek kaygısının oluşmasına neden olmaktadır. Bu bağlamda yaşlı nüfusun üretimden çekilmesi ve artan tasarrufların yatırımlara dönüşmemesi, bir taraftan üretimi azaltırken(arz yönlü); diğer taraftan gelecek kaygıs1 ve ihtiyat güdüsü ile paranın elde tutulması, tüketimi (talep yönlü) azaltmaktadır. Summers vd (2014), yetersiz toplam talebe dayanarak kalıcı durgunluk hipotezini dile getirmişlerdir. Yatırımdaki kanıtlar aksi belirtilmediğini şiddetle göstermektedir.

Kalıcı durgunluğu açıklamada arzı önceleyen teorik yaklaşımlar gelenekseldir. Ancak yaygın makroekonomiye göre, talep yetersizliği sorunlarının göz ardı edilmemesi gerekmektedir. Bu perspektife göre beş yıldan daha fazla süren durgunluk, teknik değişim oranındaki bir yavaşlamanın veya 


\section{Gelişmiş Ekonomilerde Yeni Normal: Kalıcı Durgunluk}

kurumsal yapıdaki girdileri veya teknolojiyi etkileyen olumsuz bir değişimden kaynaklanmaktadır. Bu teorik çerçeve, birçok analistin, 2007'den bu yana hayal kırıklığına uğratan makroekonomik eğilimlere dair net kanıtlara rağmen, ABD ekonomisinin yine de 2017 yılı sonlarına kadar potansiyel çıktı seviyesinde veya yakınında faaliyet göstermesi gerektiğini göstermektedir. ABD’nin Büyük Buhran'ın ilk yıllarından bu yana en büyük finansal krizi izleyen yaklaşık 10 yıldaki durgun talep artışından kalıcı bir durgunluk yaşadığı ortadadır (Cynamon ve Fazzari, 2017).

Günümüzde gelişmiş ekonomilerin üretim sorunu söz konusu değildir. Ancak artan tasarrufların yatırımlara yönelmemesinin, arz yönlü bir sorun olarak üretimi azalttığını veya toplam çıktı üzerinden negatif bir baskı yarattığını söylemek mümkündür. Tasarrufları günlük tüketimden vazgeçme olarak veya tüketimin ertelenmesi olarak tanımlarsak, artan tasarruflar bir taraftan yatırımı negatif etkilerken; diğer taraftan tüketimi dolayısıyla toplam talebi olumsuz etkilemektedir. Kalıcı durgunlukta arzı ve talebi bir birinden bağımsız olarak düşünmek ve sadece birisini etken olarak göstermek buna çözüm bulmada eksikliğe neden olacaktır.

\subsection{Para Ve Maliye Politikaları Kalıcı Durgunluğu Önlemede Ne Kadar} Etkilidir?

Para politikası ve maliye politikası, politika yapıcılarının ve ekonomi yönetiminin temel ekonomik sorunları gidermede kullandıkları temel araçlardır. Para politikası, parasal araçları kullanarak temel hedeflere ulaşmaya çalışırken; maliye politikası, kamu harcamaları ve vergi politikaları ile hedeflere ulaşmaya çalışır. Amaç, ekonomik sorunların üstesinden gelmek olduğuna göre bu iki politikanın hangi sorunlara ne gibi çözümler üreteceği önem arz etmektedir. Kalıcı durgunluğa, sorunun kaynağında yatan nedene göre hem para politikası hem de maliye politikası çözüm üretecektir. Ancak bu çözümlerin birbiriyle çelişmemesi gerekir. Ekonomi yönetimlerinin duruma çözüm getirebilmesi için öncelikle bu sorunu (kalıcı durgunluk) kabul etmeleri ve çözüm aramaları gerekmektedir.

Enflasyon hedeflemesinin uygulandığ politikalarının kalıcı durgunluğu önlemede etkili olamamama durumu söz konusudur. Gelişmiş ekonomilerde enflasyon hedefindeki bir artış, sadece tam istihdam imkanı sağlarken kalıcı durgunluğun istikrarlı durumunu ortadan kaldırmamaktadır. Diğer taraftan maliye politikası bu durumda daha etkili olacak; kamu borçlarındaki değişiklikler ve yeni dağıtım biçimleri ile kalıcı durgunluğu ortadan kaldırılabilecektir (Eggertsson vd., 2017).

Carvalho vd. (2017), yaptıkları çalışmada değişen demografik yapıda yaşlanan nüfusun, doğal faiz oranı üzerinde negatif ve uzun süreli bir etkisi olacağını göstermişlerdir. Gelişmiş ekonomilerde faiz oranlarının alt sınırın çok üstünde kalmayacağı görüşü, merkez bankalarının uzun süreli durgunluğu 
giderme ve ekonomiyi canlandırma konularında geliştirecekleri politika faiz oranlarındaki oynamalarının çok da etkili olmayacağını göstermektedir.

Grafik 3'te görüldüğü gibi finansal krizden çok önce başlayan reel faizlerdeki düşüş, hem ülkeler arasında hem de varlık sınıfları arasında geniş bir noktaya ulaşmıştır. Uzun vadede enflasyon korumalı devlet menkul kıymetlerine ilişkin getiriler, en azından 1990'ların başlarından bu yana azalış eğilimi gösterirken son on yılda en düşük seviyelerine gerilemiştir (Rachel ve Summers, 2019).

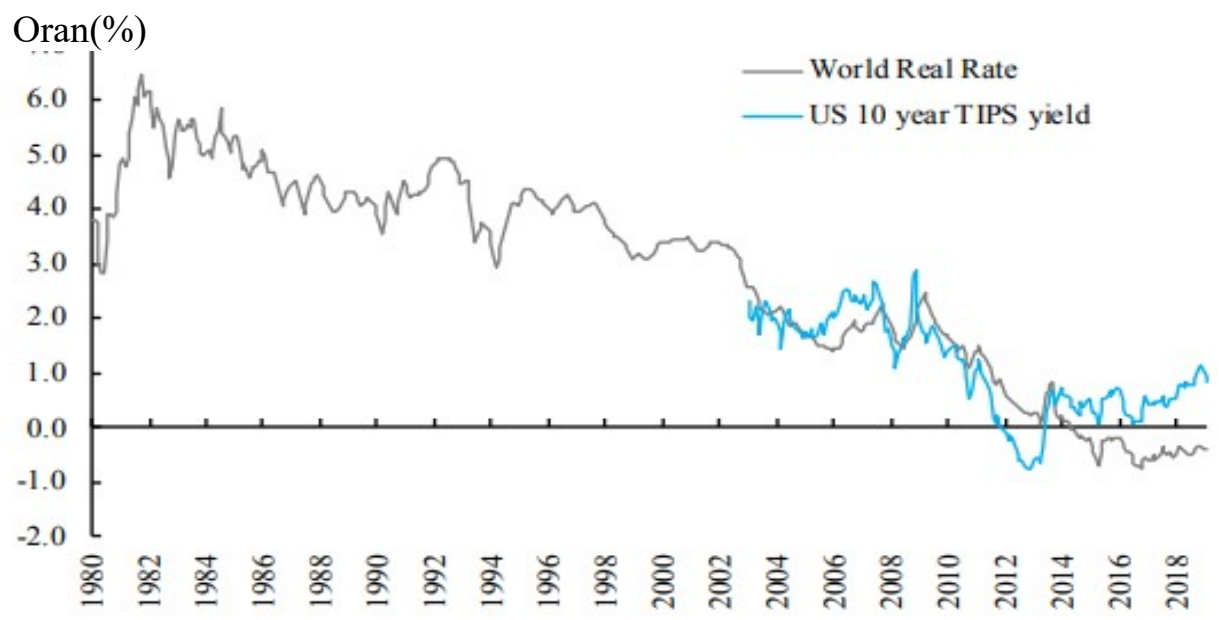

Not: Dünya reel faiz oranı İtalya hariç G7 genelinde enflasyon korumalı devlet borçlanma senetleri üzerindeki faiz oranları ortalamasıdır.

Grafik 3: Gelişmiş Ekonomilerde ve ABD'de Reel Faiz Oranları (Rachel ve Summers, 2019).

Günümüzde enflasyonist riskler kadar deflasyon risklerinin de olduğu, arz yetersizliği gibi talep yetersizliğinin yaşandığı bir dünya söz konusudur. Böyle bir dünyada para politikasının gücü konusunda sınırlar olduğu aşikardır. Bu olay bir politika meselesi değil, ekonomik bir gerçeklik meselesidir. Farklı ekonomik koşullar, farklı ekonomik politika çözümü gerektirecektir ve bu durum, hem para politikası sorumluluğu ile yüklenenlerin hem de para politikasının faaliyet gösterdiği politik çerçeveleri oluşturanların, kalıcı durgunluk döneminde çok fazla akılda tutması gerektiği bir şeydir (Summers, 2016).

Nominal faiz oranlarının çok düşük seviyelerde olması, para politikasının durgunluğu önlemede çözümün bir parçası olmayacağı anlamına gelmemektedir. Ancak görünen odur ki, kalıcı durgunluğu önlemede kamu yatırımlarının artmasının çok önemli bir etkisi olacaktır. Bu durum maliye politikasının çok önemli bir rol oynaması gereğini ortaya koymaktadır. Wolf (2014), son yıllarda Euro bölgesindeki en büyük sorunlardan birinin kamu yatırımlarındaki artışın düşük olması olarak belirtmiştir. $\mathrm{Bu}$ zayıflı̆̆ın Almanya'da daha fazla kamu yatırımlarıyla çözülmesi gerekmektedir. Ayrıca, 


\section{Gelişmiş Ekonomilerde Yeni Normal: Kalıcı Durgunluk}

yeni ve daha iyi enerji kaynakları ile dijital ağlar gibi kamu mallarına Avrupa düzeyinde yatırım yapılmalıdır. Bu durum, kalıcı durgunluğu gidermek için kamu yatırımları ve yeni yatırım firsatlarına ihtiyaç olduğunu göstermektedir.

Dengeli bütçe kalıcı durgunluk için bir reçete olabilir. Eğer politika yapıcılar, toplam talebin azalmasından kaçınmak istiyorlarsa, yükselen kamu açıklarını ve devlet borç seviyelerini kabul ederek, sıfıra yakın veya negatif reel faiz oranlarıyla bir şekilde yaşamaya alışmalı ve yapısal politikaları bulmak için bir şeyler yapmalıdırlar. Bu durum yatırımları teşvik edecek veya tasarrufları azaltacaktır (Rachel ve Summers, 2019). Maliye politikası ve kamu harcamaları devlet teşvikleri, tüketimi arttırıcı bir etki yapacağından ekonomiye canlılık getirecektir. Kalıcı durgunluğun önlenmesinde etkin ve yapısal bir şekilde kullanılması durumunda maliye politikasının etkili olabileceğini söylemek mümkündür. Özellikle faiz oranlarının sıfır bandında olması, para politikasının ek gevşemeye giderek piyasayı canlandırması olanaksızdır.

\subsection{Gelişmekte Olan Ülkeler ve Kalıcı Durgunluk}

Yaşanan bir ekonomik krizin ya da herhangi bir ekonomik olgunun sadece bir ya da birkaç ülkeyi etkilediğini söylemek, günümüz bilgi ve dijital çağında mümkün değildir. Sebep-sonuç ilişkisi içerisinde küresel ekonomide her gelişmenin yarattığı bir etki ve dalga söz konusudur. Bu bağlamda gelişmiş ekonomilerde yaşanan kalıcı durgunluğun gelişmekte olan ekonomilere etkisi, olumlu ya da olumsuz olarak tezahür edecektir.

Son zamanlara kadar gelişmiş sanayi toplumlarının en önemli büyüme kaynakları, kolayca ulaşabildikleri gelişmemiş ya da gelişmekte olan toplumların hammadde yataklariydı. Kısaca bu toplumlar, zenginliklerini bol hammadde kaynaklarının üzerine oturtmuşlardı. Gelişen bilim ve teknoloji ile birlikte gelişmekte olan ülkelerin kendi kaynaklarını kullanma yönünde refleks göstermeye başlamaları, gelişmiş ve kalıcı durgunluk aşamasına gelen toplumların daha az bir kaynakla maksimum çıktıyı sağlamalarını zorunlu hale getirmiştir. Günümüzde değişen güç dengeleri, özellikle gelişmekte olan ülkeler kategorisinde olan Çin ve Rusya'nın dünya ekonomi pazarında aktif rol alması, Amerika ve Avrupa Birliği gelişmişlerini yeni politika arayışlarına sürüklemektedir. Durgunluğu önleme konusunda daha önceleri demokratikleştirme hamleleri yapan ve yeni pazar yaratan ülkeler, istedikleri sonucu almakta artık zorlanmaktadırlar.

2018 yılı dünya ekonomisi ortalama büyüme rakamlarına bakıldığında, $\% 3$ gibi bir büyüme beklentisi söz konusudur. Dünya büyümesini yukarıya iten temel ekonomiler, Hindistan (\% 7), Çin (\% 6) ve Misır (\% 5) ekonomileri olurken; gelişen ekonomiler aşağıya doğru bir baskı yaratmaktadır. Euro bölgesinde \%1 seviyesinde bir büyüme beklenirken, Amerika Birleşik Devletleri ve Japonya'da bu rakam \%2 seviyesinde seyretmektedir.

Kalıcı durgunluk, Türkiye gibi gelişmekte olan ülkeleri olumlu etkileyebileceği gibi olumsuz da etkileyebilir. Gelişmiş ekonomilerde 
tasarrufların yatırıma dönüşmesindeki yavaşlık, bu ekonomilere yapılacak ihracatın düşmesine neden olacaktır. Bu bağlamda özellikle üretim ara malı ve hammadde ihracat talebi, kalıcı durgunluk yaşayan ülkelerde düşecektir. Diğer taraftan kalıcı durgunluğun sonucu olarak sermaye ve fon getirisi elde edemeyen yatırımcılar, doymuş piyasalardan kaçarak doymamış piyasalara akın etmektedir. Bu durum, 2007-2008 finansal kriz döneminde, hemen hemen bütün gelişmiş ülkelerin krizin etkisini uzun süre yaşaması ve gelişmekte olan ülkelerin krizden hemen sonra tekrar yüksek büyüme rakamlarına ulaşmasıyla kendisini göstermiştir. 2009 yıll, kriz etkisinin Türkiye'de yoğun olarak yaşandığ 1 bir yıl olmuş ve bu dönemde ekonomi \% 4 oranında küçülmüştür. Ancak yukarıda belirtildiği gibi 2010 yılında, yoğun sermaye akımları alan Türkiye ekonomisi \% 9 oranında büyüme sağlamıştır.

$\mathrm{Az}$ gelişmişlik eğer kendi kaynaklarını kendi bilim ve teknolojisini kullanarak geliştirmezse süreklilik arz edecektir. Gelişmiş toplumlar ile gelişmekte olan toplumlar arasındaki fark, ancak kaynak kullanımı konusunda ülkelerin kendi değerlerini idare etmesi ile kapanabilecektir. Son dönemlerde gelişmekte olan toplumların toplam çıktı atağı, dünya büyüme ortalamasını yükseltirken; bu toplumların gelişmiş kategoriye yaklaşmasına vesile olmaktadır. Ancak bu durumu bütün gelişmekte olan ülkeler için söylemek mümkün değildir.

\section{Sonuç}

Kalıcı durgunluk, gelişmiş ekonomilerde yaşanan, az gelişmiş ve gelişmekte olan ekonomileri de bir şekilde etkileyen dinamik bir süreç olarak devam etmektedir. Demografik değişiklik, teknolojik düzeyin neredeyse "üretim arttırıcı yönüyle" sona yaklaşması, gelir dağılımı dengesizliği, üniversite mezunu genç işsizliğinin artması, kamu ve özel sektör borç seviyelerinin yükselmesi ve artan finansalizasyon, başka bir deyişle üretim kapitalizminin finans kapitalizmine dönüşmesi, günümüz ekonomik ortamını içinden çıkılmaz bir hale sokmuştur. Özellikle globalleşme ile birlikte çok uluslu dev firmaların dünya ekonomisinde büyük paylar elde etmesi, hem siyasi hem de ekonomi yönetimlerinin kamu yararına politikalar geliştirmesi önünde engel olmaya başlamıştır. Kamu kaynaklarının bölüşümü konusunda büyük bir dengesizlik söz konusudur. Liberal ekonominin temelini oluşturan bireysel teşebbüs, az sayıda güçlüyü daha güçlü hale dönüştürürken; milyonlarca açlık sınırında yaşayan topluluklar oluşturmuştur. Ekonomi yönetim kontrolünün bu azınlığın elinde olmasını, kalıc1 durgunluğun bir nedeni olarak değerlendirmek mümkündür.

Demografik değişim güçlü ekonomilerin çözmek zorunda olduğu temel sorunlardan bir tanesidir. Artan yaşam beklentisi, yaşlanan nüfus ve emeklilikte geçen sürelerin uzaması dikkat çekmektedir. Bu durum, tasarrufların yatırımlara dönüşmemesine neden olurken; tasarruf-yatırım dengesini, tasarruf lehine bozmaktadır. Tasarrufların yatırımlara dönüşmesi yönünde politikaların geliştirilmesi, gelecek kaygısı yaşayan tasarruf sahiplerinin yatırım yönlü 
hareket etmelerini sağlayacaktır. Bireysel tasarruflar, kişiyi tüketimden yoksun bırakmakta; ekonomideki toplam talepte azalış ve yatırımlarda kısılmalara neden olmaktadır. Bu anlamda bakıldığında kamu otoritesinin yani devletlerin tasarruf politikası geliştirip olayın bireysel stratejiden ziyade toplumsal geçiş stratejileri ile gerçekleştirmesi daha sağlıklı olacaktır. Diğer taraftan robotik üretim, yaşlanan toplumlar için aktif işgücü yaratma konusunda bir alternatif oluştururken; diğer taraftan yeni işsiz orduları da yaratabilecektir. Bu anlamda teknolojinin belirli bir kesimin çıkarı doğrultusunda kullanılması belki de geleceğin felaketi olacaktır.

Bazı ekonomistler yaşlanmanın etkilerinin emeklilik yaşındaki artışla dengelenebileceğini dile getirmektedir. Bu önlem, belki yaşam kalitesi ve beklentisi yüksek olan ülkelerde mümkün olabilir; ancak gelişmekte olan ülkelerde geç emekliliğin dezavantajlarını ortaya çıkarıp emeklilikten sonra insanların yaşayacakları çok da zamanlarının olmaması sorununu gündeme getirecektir. Emeklilik yaşının yükseltilmesi yerine yaşlanan gelişmiş ülkelerin bir zamanlar nüfus artış sıkıntısı yaşayan ülkelerde uygulandığı gibi artış yönlü nüfus planlamasını uzun sürede gündeme getirmeleri önerilebilir.

Büyümenin yavaşladığı, faiz oranlarının neredeyse negatif seviyelere indiği ve düşük enflasyona rağmen arz ve talep yetersizliğinin yaşandığı kalıcı durgunluk ortamında amaç büyümeyi teşvik edici yollar geliştirmektir. Mevcut ortamda büyümeyi teşvik edecek en iyi strateji ne olacaktır? Bu anlamda yapısal reformlar büyük önem arz ederken makroekonomik uyum da unutulmamalıdır. Politika yapıcılar, yapacakları eylem planlarında uygulayacakları para politikaları ile maliye politikalarının birbirini destekler nitelikte olmasına önem göstermelidirler. Kamu yararını ön planda tutan gerek para gerekse maliye politikaları, yeri geldiğinde üretim arttırıcı etki yaparken aynı zamanda tüketimi de teşvik edecek nitelikte olmalıdır. Özel sektör etkinliği gibi sosyal devlet anlayışıyla kamu sektörünün de çözüm odaklı hareket etmesi gerekmektedir. Kamu kaynakları dağıtımı, gelir dağılımı eşitliği gözetilerek yapılmalı, rekabet önleyici ve tekelci yapılar ortadan kaldırılmalıdır.

Tüm bunlarla birlikte ifade edilmelidir ki kalıcı durgunluk kavramının yeni olması ve bu alanda yeterli sayıda çalışmanın bulunmaması farklı bakış açılarıyla yeni çalışmaları zorunlu hale getirmiştir. Yapılacak ampirik çalışmalarla kavramsal olarak ele alınan kalıcı durgunluğun daha da detaylandırılması alana katkı sağlayacaktır.

\section{Kaynaklar}

Acemoglu, D., ve Restrepo, P. (2017). Secular Stagnation? The Effect of Aging on Economic Growth in the Age of Automation. American Economic Review: Papers ve Proceedings, 107(5), 174-179.

Blanchard, O., ve Summers, L. H. (2019, 05 13). Secular Stagnation Requires Rethinking Macroeconomic Policy, Especially Fiscal Policy. 07 24, 2019 tarihinde Peterson Institute For İnternational Economics: 
https://www.piie.com/blogs/realtime/economic-issues-watch/secularstagnation-requires-rethinking-macroeconomic-policy adresinden alınd1 Carvalho, C., Ferrero, A., ve Nechio, F. (2017). Demografic Ttransition and Low U.S. İnterest Rate. FRBSF Economic Letter, 27.

Cynamon, B. Z., ve Fazzari, S. M. (2017). Secular Demand Stagnation in the 21 st Century U.S. Economy. Preliminary draft prepared for INET Secular Stagnation Conference.

Eggertsson, G. B., Mehrotra, N. R., ve Robbins, J. A. (2017). A Model of Secular Stagnation: Theory and Quantitative Evaluation. Cambridge: Nber Working Paper Series.

Eichengreen, B. (2014, 08 15). Secular stagnation: A review of the issues. 07 18, 2019 tarihinde https://voxeu.org: https://voxeu.org/article/secularstagnation-review-issues adresinden alındı

Galbraith, J. K. (2018). The great financial crisis and the end of normal. A note prepared for the Association of Social Economics Session on the Economic and Financial Crisis after 10 Years. Philadelphia PA.

Gomme, B., Ravikumar, B., ve Rupert, P. (2015). Secular Stagnation and Returns on Capital. Economic Synopses.

Gordon, R. J. (2014). The turtle's progress: Secular stagnation meets the headwinds. C. Teulings, ve R. Baldwin içinde, Secular Stagnation: Facts, Causes and Cures (s. 41-59). London: Centre for Economic Policy Research (CEPR).

Hansen, A. H. (1939). Economic Progress and Declining Population Growth. The American Economic Review, 29(1), 1-15.

Jimeno, J. F., Smets, F., ve Yiangou, J. (2014, 09 15). Secular stagnation: A view from the Eurozone. 07 19, 2019 tarihinde VOX CEPR Policy Portal: https://voxeu.org/article/secular-stagnation-view-eurozone adresinden alınd 1

Krugman, P. (2010). Bunalım Ekonomisinin Geri Dönüşü ve Küresel Kriz. İstanbul: Literatür.

Onaran, Ö. (2016). Secular Stagnation and progressive economic policy alternatives. European Journal of Economics and Economic Policies: İntervention, 13(2), 229-240.

Piketty, T. (2014). Yirmi Birinci Yüzyılda Kapital. İstanbul: Türkiye İş Bankası Kültür Yayınları.

Rachel, L., ve Summers, L. H. (2019). On falling neutral real rates, fiscal policy, and the risk of secular stagnation. Brooking Papers On Economics Activity BPEA Conference Drafts, March 7-8.

Summers, L. (2016, 02 15). The Age of Secular Stagnation. 08 01, 2019 tarihinde Larry Summers: http://larrysummers.com/2016/02/17/the-ageof-secular-stagnation/ adresinden alındı

Summers, L. H. (2015). Demand Side Secular Stagnation. American Economic Review: Papers ve Proceedings, 105(5), 60-65. 
Gelişmiş Ekonomilerde Yeni Normal: Kalıcı Durgunluk

Summers, L. H. (2016). Secular Stagnation and Monetary Policy. Federal Reserve Bank of St. Louis Review, 98(2), 93-110.

Toffler, A. (1996). Ekonominin Çöküşü Eko-Spazm. İstanbul: İnsan Yayınları.

Wallerstein, İ. (2016). Tarihsel Kapitalizm ve Kaptalist Uygarlı. İstanbul: Metis Yayınları.

Wolff, G. B. (2014). Monetary policy cannot solve secular stagnation alone. C. Teulings, ve R. Baldwin içinde, Secular Stagnation: Facts, Causes and Cures (s. 143-150). London: Centre for Economic Policy Research (CEPR). 